\title{
ПОРАЖЕНИЕ НЕРВНОЙ СИСТЕМЫ И ОРГАНИЗАЦИЯ КОМПЛЕКСА ЛЕЧЕБНЫХ И РЕАБИЛИТАЦИОННЫХ МЕРОПРИЯТИЙ У БОЛЬНЫХ С ВИЧ-ИНФЕКЦИЕЙ
}

\author{
${ }^{1}$ Юсупов Ф.А.*, ${ }^{2}$ Абдыкалыкова Н.С. \\ ${ }^{1}$ Ошский государственный университет, зав. каф. неврологии нейрохирургии и психиатрии, Ош, \\ Кьргызгтан; \\ ²Зав. отделением неврологии Ошской Обьедененной клинической больницы, Оu, Кыргызстан
}

$\mathrm{H}$ есмотря на предпринимаемые меры, число лиц живущих с ВИЧ в мире продолжает расти, и к 2011 году составило 34,2 млн. человек (6).

Наиболее высокий темп роста эпидемии ВИЧ инфекции наблюдается в Восточной Европе и Центральной Азии, куда входит и Кыргызстан (6).

Неврологическая патология при ВИЧ-инфекции имеет чрезвычайно важное значение, достигая степени самостоятельной проблемы - НейроСПИД. Высокая частота неврологических проявлений при ВИЧ-инфекции, а также трудности ранней диагностики, проведения дифференциальной диагностики подчеркивают значительную актуальность и приоритетность проблемы СПИДа в мировой клинической медицине и,в неврологии в частности $(3,4)$.

Клинические проявления ВИЧ-инфекции характеризуются вовлечением в патологический процесс многих органов и систем, в том числе и нервной системы. Поражение ее встречается у 90\% больных, а у 10-20\% больных неврологические проявления могут быть первыми признаками заболевания (3).

Поражение нервной системы при ВИЧ-инфекции стоит на втором месте по значению после иммунной. Это связано с множеством патогенетических механизмов поражения как центральной, так и периферической нервной системы $(1,2,5)$.

Несмотря на значительный процент вовлеченности нервной системы диагностика ее остается затруднительной. Это связано, прежде всего, с отсутствием патогномоничных симптомов, характеризующих поражение нервной системы при ВИЧ-инфекции, дороговизной лабораторно-инструментального исследования, что приводит к запоздалой диагностике патологии, несвоевременной коррекции этиопатогенетической терапии, а также к тяжелому органическому поражению нервной системы с возможным последующим резидуальным неврологическим дефицитом.

Таким образом, лечение данной категории пациентов подразумевает длительный период времени и порой, низкую эффективность терапии, что естественно отражается не лучшим образом на мотивированности самого пациента и его родственников. В данном случае, первостепенную роль будет играть как психологическая, социальная поддержка больного и его ближайшего окружения, так и возможность получения адекватной медицинской помощи. Эти моменты составляют основу понятия "паллиативная помощь", и одним из путей предоставления которой, является внедрение системы "стационар на дому".

Учитывая вышеизложенное, представляется крайне важным выявление больных ВИЧинфекцией с поражением нервной системы, клиническая характеристика неврологических проявлений, а также улучшение доступности специализированной медицинской помощи через систему "стационар на дому".

Целью настоящего исследования явилось описание клинической симптоматики поражения нервной системы у больных с ВИЧ-инфекцией и сравнительный анализ качества жизни этой категории больных в амбулаторных условиях ("стационар на дому").

Материалы и методы исследования. Работа основана на анализе результатов наблюдения и лечения 106 больных ВИЧ-инфекцией 4В

*e-mail: furcat_y@mail.ru 
(СПИД) имевших поражения нервной системы с января 2009 по декабрь 2012 г.

Возраст пациентов колеблется от 21 по 72 лет (средний возраст составил $30,6 \pm 1,7$ года) мужчин 79 (74,5\%), женщин 27 (25,4\%) .

Всем пациентам проводился клинико-неврологический осмотр в соответствии с общепринятой методикой обследования.

Помимо стандартных лабораторных исследований крови и мочи, больным проводили диагностическую люмбальную пункцию с оценкой показателей общего и биохимического состава ликвора, анализ спинномозговой жидкости на наличие ДНК T.gondii, M.tuberculosis, ВПГ-1,2 типов, ЦМВ, ВГ-6 типа, BB3, Cr.neoformans, C.albicans, C.glabrata, C.krusei.

Осуществляли микроскопическое исследование ликвора на кислотоустойчивые бактерии и криптококки. Всем пациентам с количеством СД4-лимфоцитов менее 100 кл/мкл выполняли анализ цельной крови на наличие ДНК ЦМВ с определением концентрации ДНК ЦМВ.

Показатели системы иммунитета определяли методом проточной цитофлюорометрии с использованием моноклониальных антител. Больным проводили КТ или МРТ головного и спинного мозга, секционное исследование осуществляли в патологоанотомическом отделении ОМОКБ г.Ош.

$\mathrm{C}$ целью оказания паллиативной помощи больным с ВИЧ-инфекцией на базе кафедры неврологии и неврологического центра "Рефлекс" был организован "стационар на дому".

Нами были составлены положение о "стационаре на дому": организационная структура, должностные инструкции медицинского персонала, табели оснащения.

Для работы в "стационаре на дому" за счет внутренних резервов медицинского факультета ОшГУ, кафедры неврологии и неврологического центра "Рефлекс" и ООЦПБС был выделен врач-невролог, врач-инфекционист, медицинская сестра, реабилитолог, социальный работник (специалист по социальной работе), психотерапевт, равный консультант из представителей сообщества ЛжВ на базе цен- тра ООЦПБС.

В условиях "стационара на дому" наряду с высокоактивной антиретровирусной терапией (ВААРТ) лечебные мероприятия были комплексными с учетом тяжести состояния больного. Особое внимание уделяли предупреждению вторичных осложнений (пролежней, уросептических осложнений и т.п). В связи с чем, родственников обучали необходимым правилам ухода за больным. По окончанию полного курса лечебно-реабилитационных мероприятий ежемесячно проводились активные посещения на дому.

При обработке данных вычисляли доверительный коэффициент Стьюдента. Различия между сравнительными показателями по разным критериям считали достоверными при уровне значимости не менее $95 \%$.

Результаты исследования и их обсуждения. Наши наблюдения показали, что неврологические проявления ВИЧ-инфекции были представлены разнообразной симптоматикой, включавшей поражение практически всех отделов нервной системы.

У 63 больных мы наблюдали клинический синдром подкорково-лобной деменции (ВИЧ-энцефалопатия), ядром неврологической симптоматики которой явились когнитивные нарушения - расстройства внимания, памяти, интеллекта в сочетании с эмоционально-поведенческими расстройствами (эмоциональная лабильность, депрессия, апатия, психомоторная заторможенность). Двигательные нарушения проявлялись синдромом паркинсонизма у 14 больных, миоклоническим гиперкинезом у 2 больных, у 4 пациентов мозжечковыми и пирамидными симптомами, у 2 больных имел место спастический парез ног с сенситивной атаксией. Эпилептические припадки мы наблюдали у 3 больных.

При исследовании спинномозговой жидкости у 41 больных отмечалось умеренное увеличение содержания белка. На МРТ выявлялась церебральная атрофия с расширением корковых борозд и желудочковой системы.

У 12 больных имела место дистальная симметричная невропатия, которая проявлялась выраженными болями в ногах, парестезиями 
и жжением в стопах. Вышеуказанные симптомы сопровождались снижением или выпадением ахилловых рефлексов при сохранности коленных, а также гипестезией поверхностной чувствительности по типу "носков", трофическими и вазомоторными нарушениями на нижних конечностях.

У 8 больных было выявлено сочетание клинических проявлений дистальной сенсорной полиневропатии и ВИЧ-энцефалопатии. У 3 больных клиника поражения нервной системы проявлялась в виде синдрома ГийенаБарре со всеми неврологическими атрибутами. У 2 больных мы наблюдали симптомы множественной мононевропатии, причем у одного явления поражения лицевого нерва с обеих сторон рецидивирующего характера.

У 8 больных был выявлен церебральный токсоплазмоз (токсоплазмозный энцефалит), в 3 случаях имело место сочетанное поражение головного мозга, сердца и легких. Клинически токсаплазмозный энцефалит проявлялся общемозговой и очаговой симптоматикой: почти все больные жаловались на диффузную головную боль; гемипарез наблюдали у 3 больных, гемианопсию у 2, экстрапирамидные нарушения у 4, а у 1 больного эпилептический синдром. Следует отметить, что ни у одного больного мы не наблюдали менингеальной симптоматики.

Диагноз токсоплазмозный энцефалит подтверждался проведением КТ (у 3 больных) и МРТ (у 4 больных), серологическими методами исследования.

Среди вирусных инфекций, осложнивших течение ВИЧ и приведших к поражению нервной системы мы наблюдали цитомегаловирусную инфекцию у 3 больных, простой герпес у двух больных и опоясывающий лишай у 1 больного.

У 3 больных ВИЧ-инфекцией удалось выявить туберкулезный менингоэцефалит с очагом туберкулезной инфекции в легких. Острое нарушение мозгового кровообращения имело место у 2 больных, причем у обоих оно протекало по типу ишемического инсульта, подтвержденным МРТ исследованием головного мозга.

\section{Оценка эффективности лечения больных в} условиях "стационара на дому". Анализ результатов исследования показал, что к концу периода наблюдения из 106 больных ВИЧинфекцией на стадии 4В(СПИД) имевших поражение нервной системы у 43 (41\%) больных имел место летальный исход. Выжило 63 человека из них 44 (69,8\%) больных нуждались в постороннем уходе, $12(19 \%)$ не нуждались в нем и частично зависели от помощи окружающих 7 (11\%) больных.

С целью оценки эффективности лечения больных в условиях "стационара на дому" нами проведен сравнительный анализ клиникофункциональных исходов между больными, лечившимися в "стационаре на дому" (36 больных) с группой больных (70 человек) получивших на дому неспециализированную помощь. Обе группы были сопоставлены по полу, возрасту, тяжести течения и количеству больных получивших ВААРТ.

При сравнительной оценке летальности в этих двух группах наименьший показатель наблюдался в I (основной) группе, где из 36 больных умерло 9 (25\%)человек, тогда как во II (контрольной) группе из 70 больных умерло $34(48,5 \%)$ человек $(\mathrm{p}<0,05)$.

Количество пациентов независящих от окружающих в повседневной жизни в условиях "стационара на дому" составило 10 человек $(37,0 \%)$, а среди больных контрольной группы лишь $2(5,5 \%)$ человека.

$5(18,5 \%)$ больных в I группе частично зависели от посторонней помощи, тогда как во II группе аналогичный результат имел место у $2(5,5 \%)$ больных.

Из них 27 выживших больных в условиях "стационара на дому" - 14 (51,8\%) человек нуждались в постороннем уходе, в то время как в контрольной группе этот показатель равнялся $30(83,3 \%)$.

Таким образом, достигнутые в сравнительно короткий срок, при минимальных экономических затратах положительный сдвиг в оказании медицинской помощи больным с ВИЧ-инфекцией с поражением нервной системы во внебольничных условиях позволяет отнести "стационар на дому" к достаточно эффективным 
организационным способам борьбы с этим заболеванием и указывает на необходимость его дальнейшего сушествования и более широкого внедрения в практику здравоохранения.

\section{Выводы}

1. Поражение нервной системы является одним из грозных осложнений ВИЧ-инфекции приведших к летальному исходу в 41,0\% случаев.

2. Исследования показали, что создание "стационара на дому" является перспективной амбулаторно-поликлинической формой оказания медицинской помощи населению, позволяющей проводить обследование, лечение и профилактические мероприятия больным с ВИЧ-инфекцией, имеющих поражение нервной системы.

\section{ЛИТЕРАТУРА}

1. ВИЧ- инфекция и СПИД/ под редакцией В.В. Покровского.- 2-е изд.-//М., ГЭОТАР МЕД.-2010. 2. В.В. Беляева, В.И. Шахгильдян, А.В. Кравченко "Деменция как проявление цитомегаловирусного энцефалита у больных СПИДом"//Журнал невр. и псих.-1999.-Т.99, №4.

3. А.А. Скоромец "Соматоневрология", руководство для врачей, серия "Руководство для врачей"
3. Ежедневные наблюдения специалистов за больными в условиях "стационара на дому" с первых дней заболевания способствуют своевременной диагностике характера поражения нервной системы при ВИЧ-инфекции, оказанию в более полноценном объеме патогенетической терапии, что позволяет существенно снизить удельный вес летальных исходов $(25,0 \%)$ и повысить реабилитационный потенциал у выживших $(37,0 \%)$.

4. Практический опыт показал, что внедрение "стационара на дому" повышает качество жизни людей, живущих с ВИЧ, и оказывает положительное влияние на эффективность лечения, формируя ответственное отношение пациентов к собственному здоровью, повышая приверженность к ВААРТ.

под общей редакцией С. И. Рябова, 2009 г. 4. Н.А. Яковлев, Н.М. Жулев, Т.А. Слюсарь "НейроСПИД, неврологические расстройства при ВИЧ- инфекции/СПИДе". М.-2005.

5. Eggers C., Vortmeyer F., Emskotter T. Cerebral toxoplasmosis in a patient with the AIDS presenting as obstructive hydrocephalus// Clin. Neuropathol.-1995.-V14.

6. UNAIDS доклады 2010, 2011 г.

\title{
SUMMARY
}

\section{AFFECTION OF NERVOUS SYSTEM OF THE PATIENTS WITH HIV AND ORGANIZATION OF TREATMENT AND REHABILITATION MEASURES}

\author{
${ }^{1}$ F.A.Iusupov, ${ }^{2}$ N.S.Abdykalykova \\ ${ }^{1}$ Osh State University, chair of neurology and psychiatry, Osh, Kirgizistan \\ ${ }^{2}$ Osh Interregional Clinical Hospital, Osh, Kirgizistan
}

The number of HIV patients is still increased in spite of all undertaken measures. Damage of nervous system by HIV is independent and very important problem due to high frequency of neurological complications of HIV, difficulties of early diagnostics and problems of differential diagnostics with other neurological diseases. Data in this report proves that the affection of the nervous system in HIV patients is one of the most dangerous complications lead to death. Introduction of such system as "in-patient treatment at home" can lead to better effectiveness of pathogenesis treatment, decreases bad outcomes of the patients and improves the quality of life of such group of patients.

Key words: patients with HIV, damage of nervous system, "in-patient treatment at home". 


\title{
XÜLASə
}

\section{IIV OLAN XəSTəLӘRDə SINIR SISTEMININ ZəDӘLӘNMəSI Və MÜALICO Və REABİLITASIYYA TODBİRLORININ TOŞKILLI}

\author{
${ }^{1}$ F.A.Yusupov, ${ }^{2}$ N.S.Abdykalykova \\ ${ }^{1}$ Oş Dövlat Universiteti, Nevrologiya və Psixiatriya kafedrası, Oş, Qırğızıstan; \\ ${ }^{2} O$ ş Regionarası Klinik Xəstəxanası, Oş, Qırğızıstan
}

Həyata keçirilən bütün tədbirlərə baxmayaraq, İIV yoluxmuş xəstələrin sayı artmaqda davam edir. İİV ilə sinir sisteminin zədələnməsi müstəqil olur və İIV zamanı nevroloji ağırlaşmalarının yüksək tezliyi, erkən diaqnostikanın çətinliyi və digər nevroloji pozğunluqlarla differensial diaqnostika problemləri səbəbindən mühüm bir problem kimi qiymətləndirilir. Bu məqalədə təqdim olunmuş nəticələr təsdiq edir ki, İIV yoluxmuş xəstələrdə sinir sisteminin zədələnməsi - ölümlə nəticələnən ən təhlükəli ağırlaşmadır. "Evdə stasionar" kimi sistemli tədbirlərin həyata keçirilməsi mənfi nəticələrin sayını azaldan və həmin xəstə qrupunda həyat keyfiyyətini yaxşı1laşdıran patogenetik müalicənin effektivliyinin artırılması ilə nəticələnir.

Açar sözlər: İIV-li xəstələr, sinir sisteminin zədələnməsi, "evdə stasionar".

Redaksiyaya daxil olub: 02.04.2013

Çapa tövsiy olunub: 29.04.2013

Rəyçi: R.L.Hasənov, t.e.d., dosent 